\title{
Studi Komunikasi Kelompok Terapi pada Pasien Gangguan Jiwa di RSJ Dr. Soeharto Heerdjan Jakarta
}

\author{
Wilson, Suzy S. Azeharie \\ helloitsmewilson@gmail.com,suzya@fikom.untar.ac.id
}

Fakultas Ilmu Komunikasi Universitas Tarumanagara

\begin{abstract}
Dr. Soeharto Heerdjan psychiatric hospital is one of the leading psychiatric hospital in Indonesia that has been treating mentally ill patients since 1876. In the nursing activities of mentally ill patients, group communication therapy occurs. Group communication that occurs between mentally ill patients has various functions. The theory used in this study is group communication theory which includes group communication network, types of group communications, group communication functions, and verbal \& non-verbal communication. This study used descriptive qualitative approach with case study method. The informations analyzed in this study were gathered from observations and interviews of three mentally ill patients as small group and one nurse. This study aims to understand the way mental patients communicate in groups. The conclusion of this study is group communication that happened between mentally ill patients fall under the group communication network of all channels. Patients informants convey verbal messages to get to know each other, and give non-verbal messages to convey their feelings. Whereas the most visible function of group communication is social functions and persuasive functions.
\end{abstract}

Keywords: Group Communication, Mentally Ill Patients, Verbal Communication, Nonverbal Communication

\begin{abstract}
Abstrak
Rumah Sakit Jiwa Dr. Soeharto Heerdjan adalah salah satu rumah sakit jiwa ternama di Indonesia yang berdiri menangani para pasien gangguan jiwa sejak tahun 1876. Dalam kegiatan keperawatan pasien gangguan jiwa, terdapat kegiatan komunikasi kelompok terapi. Komunikasi kelompok terapi yang terjadi antar pasien gangguan jiwa ini memiliki berbagai fungsi. Teori yang digunakan dalam penelitian ini adalah teori komunikasi kelompok yang mencakup jaringan komunikasi kelompok, tipe komunikasi kelompok, fungsi komunikasi kelompok, dan komunikasi verbal dan non-verbal. Pendekatan penelitian ini adalah kualitatif deskriptif dengan metode penelitian studi kasus. Data yang akan dianalisis diperoleh dari observasi dan wawancara dengan tiga orang pasien gangguan jiwa sebagai kelompok kecil serta satu perawat. Penelitian ini bertujuan untuk memahami cara para pasien gangguan jiwa berkomunikasi dalam kelompok terapi dan fungsi komunikasi kelompok pada pasien gangguan jiwa. Kesimpulan dari penelitian ini adalah komunikasi kelompok terapi yang terjadi di RSJ termasuk dalam jaringan komunikasi kelompok semua saluran. Informan pasien menyampaikan pesan verbal untuk mengenal satu sama lain, dan memberikan pesan non-verbal untuk menyampaikan perasaannya. Sedangkan fungsi komunikasi kelompok yang paling terlihat adalah fungsi sosial dan fungsi persuasif.
\end{abstract}

Kata Kunci: Komunikasi Kelompok, Pasien Gangguan Jiwa, Komunikasi Verbal, Komunikasi Non-Verbal 


\section{Pendahuluan}

RSJ Dr. Soeharto Heerdjan adalah salah satu rumah sakit jiwa ternama di Indonesia yang berdiri menangani para pasien gangguan jiwa sejak tahun 1876 . Aktivitas keperawatan yang dilakukan di RSJ Dr. Soeharto Heerdjan Jakarta melibatkan pasien gangguan jiwa yang melakukan kegiatan bersama pasien lainnya. Hal tersebut menyebabkan terjadinya komunikasi kelompok antar pasien gangguan jiwa.

Burhan Bungin dalam bukunya berjudul Sosiologi Komunikasi mengatakan komunikasi kelompok adalah sekumpulan orang yang terdiri dari dua atau tiga orang bahkan lebih dalam himpunan atau kesatuan-kesatuan manusia yang umumnya secara fisik relatif kecil yang hidup secara kekeluargaan. Orang dalam kelompok memiliki hubungan yang intensif antara satu sama lainnya, terutama kelompok primer, intensitas hubungan orang yang terlibat dalam kelompok merupakan persyaratan utama yang dilakukan oleh orang-orang dalam kelompok tersebut (Bungin, 2008).

Kesehatan jiwa masih menjadi salah satu permasalahan kesehatan yang terpenting di dunia, terutama di Indonesia. Walaupun begitu, permasalahan kesehatan jiwa masih dianggap sepele bagi masyarakat Indonesia. Data Riskesdas 2013 menunjukkan prevalensi gangguan mental emosional yang ditunjukkan dengan gejala-gejala depresi dan kecemasan untuk usia 15 tahun ke atas mencapai sekitar 14 juta orang atau 6\% dari jumlah penduduk Indonesia. Sedangkan prevalensi gangguan jiwa berat, seperti skizofrenia mencapai sekitar 400.000 orang atau sebanyak 1,7 per 1.000 penduduk (http://www.depkes.go.id diakses pada tanggal 6 Oktober 2018 pukul 22:33 WIB).

Rusdi Maslim mengatakan masih banyak yang belum diketahui dengan pasti tentang gangguan jiwa, dan perjalanan penyakit jiwa tidak selalu bersifat kronis. Pada umumnya ditandai adanya penyimpangan yang fundamental, karakteristik dari pikiran dan persepsi, serta adanya efek yang tidak wajar atau tumpul (Yusuf, et al. 2015).

Di RSJ Dr. Soeharto Heerdjan Jakarta dalam kehidupan sehari-hari pasien gangguan jiwa terlibat dalam komunikasi kelompok terapi. Pasien gangguan jiwa saling berkomunikasi, berbagi cerita pengalaman masing-masing, serta bermain melakukan kegiatan terapi kelompok bersama. Ada lima fungsi komunikasi kelompok menurut Sasa Djuarsa Sendjaja dalam buku Burhan Bungin berjudul Sosiologi Komunikasi yaitu fungsi sosial, fungsi pendidikan, fungsi persuasif, fungsi pemecahan masalah dan fungsi terapi (Bungin, 2008).

Penulis tertarik untuk meneliti komunikasi kelompok pasien gangguan jiwa di RSJ Dr. Soeharto Heerdjan karena penulis ingin mengetahui cara pasien gangguan jiwa berkomunikasi dengan pasien lainnya. Penulis juga ingin mengetahui fungsi dari komunikasi kelompok terapi pada pasien gangguan jiwa. Alasan lainnya adalah belum ada yang pernah meneliti mengenai komunikasi kelompok terapi antar pasien gangguan jiwa.

Berdasarkan latar belakang di atas penulis merumuskan masalah sebagai berikut: Bagaimana Komunikasi Kelompok Terapi Pada Pasien Gangguan Jiwa di RSJ Dr. Soeharto Heerdjan Jakarta? Apa Fungsi Komunikasi Kelompok Terapi Pada Pasien Gangguan Jiwa di RSJ Dr. Soeharto Heerdjan Jakarta? 
Berdasarkan perumusan masalah di atas maka penulis menentukan tujuan penelitian ini adalah untuk mengetahui cara pasien gangguan jiwa berkomunikasi dalam kelompok terapi dan fungsi komunikasi kelompok pada pasien gangguan jiwa.

Tinjauan Teoretis

Gambar 1. Tinjauan Teoretis

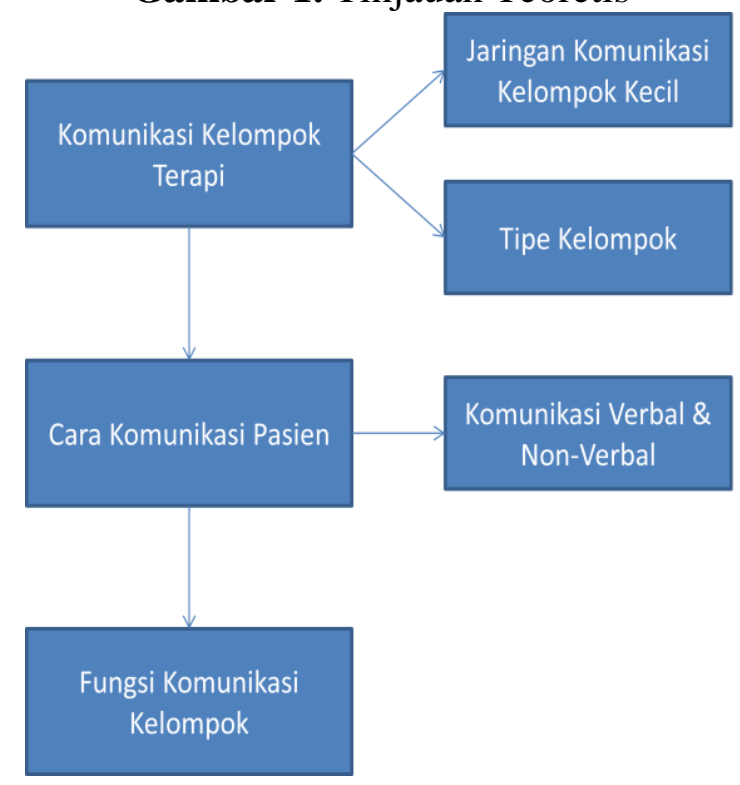

Dalam RSJ Dr. Soeharto Heerdjan Jakarta terdapat banyak pasien pengidap gangguan jiwa. Dalam kesehariannya, pasien gangguan jiwa bersama dengan pasien lainnya menjalani kegiatan komunikasi kelompok terapi bersama. Dalam komunikasi kelompok terapi itu pasien gangguan jiwa berkomunikasi secara verbal dan nonverbal, memiliki jaringan komunikasi kelompok kecil, serta termasuk dalam tipe kelompok tertentu. Melalui komunikasi kelompok terapi, terdapat fungsi-fungsi komunikasi kelompok yang muncul. Penulis ingin mengetahui bagaimana cara komunikasi pasien dalam kelompok, apa jenis jaringan komunikasi kelompoknya dan komunikasi verbal \& non-verbal yang terdapat di dalamnya, serta tipe kelompoknya. Selain itu penulis juga ingin meneliti fungsi yang ada dalam komunikasi kelompok itu.

\section{Metode Penelitian}

Dalam penelitian ini penulis memilih metode penelitian kualitatif yang bersifat deskriptif dengan pendekatan studi kasus. Metode penelitian studi kasus memungkinkan penulis untuk mempelajari dan mendalami makna, proses dan respon dalam interaksi komunikasi kelompok pasien gangguan jiwa di RSJ Dr. Soeharto Heerdjan Jakarta.

Suharsimi Arikunto dalam buku Muhammad Idrus berjudul Metode Penelitian Ilmu Sosial mengatakan subjek penelitian sebagai benda, hal atau tempat data untuk variabel penelitian melekat dan yang dipermasalahkan (Idrus, 2009). Dalam penelitian ini yang menjadi subjek penelitian adalah pasien gangguan jiwa di RSJ Dr. Soeharto Heerdjan Jakarta. Sugiyono dalam bukunya berjudul Metode Kuantitatif, Kualitatif, dan R\&D mengatakan bahwa objek penelitian adalah sasaran untuk 
mendapatkan data dengan tujuan dan kegunaan tertentu tentang suatu hal yang objektif, absah dan dapat dipercaya (Sugiyono, 2011). Dalam penelitian ini yang menjadi objek penelitian adalah komunikasi kelompok yang dilakukan pasien gangguan jiwa di RSJ Dr. Soeharto Heerdjan Jakarta.

Untuk memperkuat data penelitian maka digunakan metode pengumpulan data dengan melakukan wawancara, observasi dan studi kepustakaan dalam penelitian ini. Keempat narasumber penelitian ini adalah sebagai berikut:

1. Narasumber pertama adalah Friskila K. Tangdialla atau Ika perawat di Instalasi Rehabilitasi RSJ Dr. Soeharto Heerdjan. Ika adalah seorang perawat berumur 35 tahun yang telah bekerja sebagai perawat di RSJ Dr. Soeharto Heerdjan selama lebih dari lima tahun dan merupakan salah satu perawat yang mengurus sesi komunikasi kelompok terapi para pasien gangguan jiwa. Selama penulis melakukan observasi dan wawancara untuk penelitian penulis didampingi oleh perawat Ika.

2. Narasumber kedua adalah Putra (nama samaran) pasien gangguan jiwa berumur 45 tahun yang memiliki pendidikan terakhir S2 Manajemen di Jakarta. Putra sudah dirawat inap di Instalasi Rehabilitasi RSJ Dr. Soeharto Heerdjan Jakarta selama lebih dari satu bulan. Penyebab Putra sampai dirawat di RSJ Dr. Soeharto Heerdjan Jakarta adalah karena ia menderita skizofrenia.

3. Narasumber ketiga adalah Tobias (nama samaran) pasien gangguan jiwa berumur 36 tahun yang memiliki pendidikan terakhir SMP di Jakarta. Tobias telah dirawat inap selama lebih dari satu bulan di Instalasi Rehabilitasi RSJ Dr. Soeharto Heerdjan. Ia dirawat di RSJ Dr. Soeharto Heerdjan karena menderita gangguan bipolar. Sebelum dirawat di rumah sakit ini, Tobias bekerja membantu bisnis keluarganya berjualan baju di Jakarta.

4. Informan keempat adalah Maya (nama samaran) pasien gangguan jiwa berumur 23 tahun yang memiliki pendidikan terakhir SMP di Jakarta. Maya telah dirawat pulang selama lebih dari tiga bulan di Instalasi Rehabilitasi RSJ Dr. Soeharto Heerdjan Jakarta. Penyebab Maya sampai dirawat di RSJ Dr. Soeharto Heerdjan Jakarta karena ia menderita skizofrenia. Sebelum dirawat di rumah sakit ini Maya bekerja membantu berjualan makanan ringan di warung milik ibunya.

Teknik keabsahan data penelitian ini menggunakan triangulasi sumber data. Kriteria narasumber dalam penelitian ini adalah pasien yang mengalami gangguan jiwa, dan pasien tersebut memiliki kondisi kejiwaan yang relatif stabil dan mampu berkomunikasi dengan baik. Penulis juga dibantu oleh pihak RSJ Dr. Soeharto Heerdjan Jakarta dalam memilih narasumber yang tepat sesuai dengan topik dan pembahasan penelitian yang ingin dilakukan penulis.

\section{Hasil Temuan dan Diskusi}

Penulis meneliti komunikasi kelompok terapi pada pasien gangguan jiwa. Perawat Ika menjelaskan komunikasi kelompok terapi adalah kegiatan dalam Instalasi Rehabilitasi yang melatih para pasien untuk berkomunikasi dengan pasien lainnya. Dalam hal ini, pasien yang telah dirawat mampu berkomunikasi dengan baik dengan orang di sekitarnya. Dikatakan bahwa kegiatan komunikasi kelompok terapi sangat penting untuk para pasien gangguan jiwa, karena kegiatan tersebut dapat 
melatih pasien untuk percaya diri dalam hal berkomunikasi dan melatih pasien itu untuk bersosialisasi dengan teman dan lingkungannya. Sesi dimulai dengan perawat yang memberikan pertanyaan pada pasien sesuai dengan topik yang telah ditentukan. Setelah itu pasien akan dituntut untuk inisiatif melakukan komunikasi dengan pasien lainnya.

Perawat Ika menyatakan fungsi komunikasi kelompok dalam kegiatan komunikasi kelompok terapi adalah agar seorang pasien dapat mengenal pasien lainnya, dapat mengetahui problem masing-masing, sehingga para pasien dapat memotivasi satu sama lain. Penulis melakukan sesi komunikasi kelompok terapi bersama narasumber dua kali.

Dari sesi komunikasi kelompok terapi, melalui komunikasi para pasien gangguan jiwa dapat memberikan pesan dan respon yang bertujuan untuk saling beradaptasi atau mengenal satu sama lain. Pasien yang awalnya tertutup dan tidak terlalu banyak berbicara, menjadi lebih terbuka dan saling berbagi informasi lebih banyak. Pasien yang awalnya tegang ketika harus berkomunikasi dengan satu sama lain, menjadi lebih terbuka dan bisa bercanda dengan teman pasien lainnya.

Menurut Julia T. Wood dalam bukunya berjudul Komunikasi Teori dan Praktek komunikasi verbal adalah komunikasi melalui simbol-simbol yang telah disepakati oleh manusia dan manusia menciptakan makna serta mengkomunikasikan melewati bahasa yang dimengerti (Wood, 2013). Ketika sesi pertama komunikasi kelompok terapi Tobias, Putra dan Maya melakukan komunikasi verbal dengan memberi tahu informasi umum secukupnya saja. Tapi di sesi komunikasi kelompok terapi berikutnya, mereka melakukan komunikasi verbal yang memperlihatkan informasi lebih dalam karena sudah lebih mengenal satu sama lain. Dalam penelitian ini, informan yang paling banyak menyampaikan pesan verbal adalah Maya, sedangkan Tobias paling sedikit menyampaikan pesan verbal.

Para pasien dalam komunikasi kelompok terapi berkomunikasi secara nonverbal untuk menunjukkan perasaannya. Komunikasi non-verbal yang terjadi adalah ekspresi wajah Tobias, Putra dan Maya pada saat awal sesi komunikasi kelompok terapi dengan penulis terlihat tegang dan tertutup, karena mereka belum terlalu mengenal satu sama lain. Tetapi wajah mereka terlihat lebih terbuka dan tenang setelah mengikuti sesi komunikasi kelompok terapi berikutnya, karena mereka menjadi lebih mengenal satu sama lain melalui komunikasi kelompok. Putra menepuk pundak Tobias ketika bercanda untuk menunjukkan rasa keakraban. Raut wajah Tobias terlihat sedih ketika ia bercerita tentang awal mula bisa sampai dirawat di Instalasi Rehabilitasi, raut wajahnya menunjukkan perasaan Tobias yang sedih.

Kualitas suara para pasien lebih terdengar jelas di akhir sesi pertama komunikasi kelompok terapi dan sesi kedua komunikasi kelompok terapi, dibandingkan pada awal sesi pertama. Kualitas suara Putra berubah menjadi lebih pelan dan dalam ketika memberikan nasihat pada Maya. Kualitas suara Tobias menjadi lebih pelan ketika ia dengan sedihnya bercerita tentang kakaknya yang tega membawanya ke RSJ Dr. Soeharto Heerdjan Jakarta. Kualitas suara Maya berubah ketika ia berusaha untuk bercanda dengan Tobias dan Putra (Budyatna dan Ganiem, 2011).

Menurut Ronald B. Adler dan George Rodman dalam bukunya berjudul Understanding Human Communication terdapat tiga jenis jaringan komunikasi kelompok kecil, yaitu jaringan semua saluran, jaringan rantai dan jaringan roda. Berdasarkan analisis penulis jaringan komunikasi kelompok terapi yang terjadi di 
RSJ Dr. Soeharto Heerdjan Jakarta antara Putra, Tobias dan Maya termasuk dalam jaringan komunikasi kelompok semua saluran.

Gambar 2. Jaringan Komunikasi Kelompok Maya, Putra dan Tobias

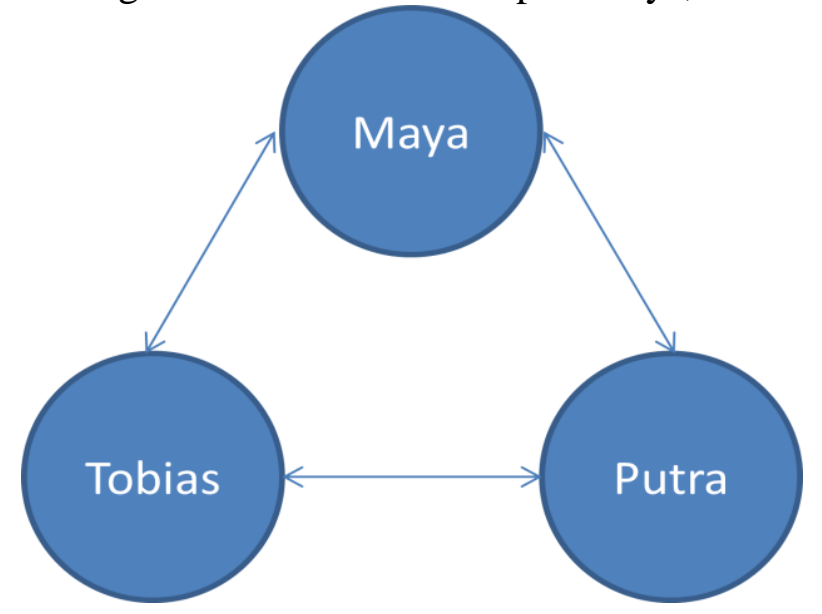

Dalam komunikasi kelompok terapi, Putra, Maya dan Tobias saling berbagi informasi antar satu dengan lainnya. Tidak ada perantara yang menyampaikan pesan. Tobias bercerita awal mula ia bisa sampai masuk dan dirawat di RSJ, kemudian Maya dan Putra ikut bercerita tentang awal mula mereka sampai dirawat di RSJ. Maya bertanya pada Tobias, Tobias bertanya pada Putra, dan Putra bertanya pada Tobias.

Ronald B. Adler dan George Rodman membagi tipe kelompok menjadi empat yaitu kelompok belajar, kelompok pemecah masalah, kelompok pertumbuhan, dan kelompok sosial. Dalam kelompok komunikasi pasien gangguan jiwa di RSJ Dr. Soeharto Heerdjan Jakarta, tipe kelompok komunikasi yang paling terbentuk adalah kelompok belajar dan kelompok sosial.

Setelah melewati dua sesi komunikasi kelompok terapi, Maya belajar cara untuk berkomunikasi dengan baik. Maya juga banyak mendapat pengetahuan tentang apartemen yang didapatnya dari Putra yang pernah bekerja di apartemen. Putra belajar cara untuk menstabilkan emosi agar tidak mengalami halusinasi, sehingga komunikasi kelompok membantunya untuk mencegah terjadinya hal tersebut. Tobias belajar cara untuk menjaga emosi, sikap dan perilakunya. Maya memberi masukan pada Putra agar tidak terlalu kaku. Putra memberi tahu Tobias untuk belajar menghitung uang agar ia bisa berdagang dengan lancar.

Pasien dalam kelompok yang awalnya tertutup, menjadi lebih terbuka dan berbagi pengalaman serta pengetahuan antar satu sama lain. Tidak jarang juga mereka saling bercanda. Putra bercanda mengatakan Tobias tidak bisa menghitung uang dengan baik dan bisa-bisa dibohongi jika membuka usaha. Tobias bercanda mengatakan Putra terlihat sangat kaku dan seperti orang tidak sehat. Maya bercanda dengan mengatakan Putra badannya seperti security tetapi hati hello kitty, sedangkan Tobias badan hello kitty tetapi hati security. Maya bercerita tentang awal mula ketika ia dipaksa oleh ibunya dan ditarik oleh ayah tirinya untuk masuk ke RSJ Dr. Soeharto Heerdjan. Putra bercerita awal mula ia mendengar suara-suara bisikan yang mengganggunya ketika sedang bekerja, sampai akhirnya orang tua Putra membawanya ke Instalasi Rehabilitasi. Tobias dengan raut muka sedih bercerita tentang awal mula dirinya tidak sadar dibawa ke RSJ Dr. Soeharto Heerdjan Jakarta oleh kakaknya (Adler dan George, 2006:267). 
Menurut Sasa Djuarsa Sendjaja dalam buku Burhan Bungin berjudul Sosiologi Komunikasi terdapat lima fungsi komunikasi kelompok, yaitu fungsi sosial, pendidikan, persuasif, pemecah masalah dan terapi. Dalam komunikasi kelompok pasien gangguan jiwa di RSJ Dr. Soeharto Heerdjan Jakarta, fungsi komunikasi kelompok yang paling terlihat adalah fungsi sosial dan persuasif.

Dalam sesi komunikasi kelompok terapi Tobias, Putra dan Maya dapat berkomunikasi secara lebih terbuka dan intens. Mereka bercerita tentang proses awal mula masuk ke RSJ Dr. Soeharto Heerdjan Jakarta yang tidak mereka ceritakan ke pasien lainnya. Tobias, Maya dan Putra saling mengaku bahwa dirawat di RSJ bukanlah keinginan mereka sendiri.

Putra memberi saran dan motivasi kepada Maya untuk tidak mendengarkan suara bisikan skizofrenia dan banyak berdoa. Tobias juga menyarankan Maya untuk tidur pada jam sembilan malam agar ia memiliki waktu tidur yang cukup. Putra memberi tahu Tobias untuk belajar menghitung lebih baik lagi, agar usaha bisnis yang ingin ia jalankan kelak bisa berjalan lancar. Setiap pasien dalam kelompok saling mempengaruhi satu sama lain (Bungin, 2008).

\section{Simpulan}

Komunikasi yang terjadi di antara pasien gangguan jiwa di RSJ Dr. Soeharto Heerdjan dalam kelompok terapi termasuk dalam jaringan komunikasi kelompok semua saluran. Para pasien dalam komunikasi kelompok terapi berkomunikasi dengan cara menyampaikan pesan verbal untuk saling mengenal satu sama lain. Ketika sesi pertama komunikasi kelompok terapi Putra, Tobias dan Maya melakukan komunikasi verbal dengan memberi tahu informasi umum secukupnya saja. Tapi pada sesi komunikasi kelompok terapi berikutnya, mereka melakukan komunikasi verbal yang memperlihatkan informasi lebih dalam karena sudah lebih mengenal satu sama lain.

Para pasien dalam komunikasi kelompok terapi berkomunikasi secara nonverbal untuk menunjukkan perasaannya. Ekspresi wajah Putra, Tobias dan Maya terlihat lebih tegang ketika awal sesi pertama komunikasi kelompok terapi. Maya dan Putra memperlihatkan wajah tersenyum dan tertawa ketika bercanda, Tobias memperlihatkan wajah sedih ketika bercerita tentang awal mula ia sampai dirawat di RSJ. Kualitas suara Putra berubah menjadi lebih pelan dan dalam ketika memberikan nasihat pada Maya. Kualitas suara Tobias menjadi lebih pelan ketika ia dengan sedihnya bercerita tentang kakaknya yang tega membawanya ke RSJ Dr. Soeharto Heerdjan Jakarta.

Dalam komunikasi kelompok terapi pasien gangguan jiwa di RSJ Dr. Soeharto Heerdjan Jakarta, tipe kelompok komunikasi yang paling terbentuk adalah kelompok belajar dan kelompok sosial, sedangkan fungsi komunikasi kelompok yang paling terlihat adalah fungsi sosial dan persuasif.

\section{Ucapan Terima Kasih}

Penulis mengucapkan terima kasih kepada seluruh pihak yang telah membantu penulis menyelesaikan penulisan skripsi ini baik secara langsung maupun tidak langsung. 


\section{Daftar Pustaka}

Ah. Yusuf, Rizky Fitryasari PK, \& Hanik Endang Nihayati. (2015). Buku Ajar Keperawatan Kesehatan Jiwa. Jakarta: Salemba Medika.

Anggariani, A., \& Suzy S. Azeharie. (2017). Komunikasi Kelompok Kecil Penyandang Kanker Anak Di Rumah Sakit Kanker Dharmais Jakarta. Jurnal Komunikasi.

Budyatna, Muhammad dan Leila M. Ganiem (2011). Teori Komunikasi Antarpribadi. Jakarta: Kencana.

Bungin, Burhan. (2008). Sosiologi Komunikasi. Jakarta: Kencana.

Idrus, Muhammad. (2009). Metode Penelitian Ilmu Sosial. Yogyakarta: PT. Gelora Akasara Pratama.

Sugiyono. (2011). Metode Penelitian Kuantitatif, Kualitatif dan R\&D. Bandung: Alfabeta.

Wood, Julia T. (2013). Komunikasi Teori dan Praktek (Komunikasi Dalam Kehidupan Kita). Jakarta: Salemba Humanika.

http://www.depkes.go.id 